\title{
PRIMER COLOQUIO DE CULTURA VISUAL: EXPLORACIÓN A LA CULTURA VISUAL MACHALEÑA DESDE EL CRITERIO DE EXPERTOS
}

FIRST COLLOQUIUM OF VISUAL CULTURE: EXPLORATION OF THE MACHALEÑA VISUAL CULTURE FROM EXPERT'S CRITERIA

\section{RESUMEN}

Este trabajo de investigación presenta un acercamiento al estado de la cultura visual en Machala, provincia de El Oro, a través de un estudio analítico con bases contextuales. Su objetivo es explorar la visión contemporánea que se tiene sobre el Cantón desde diferentes aristas de reflexión relacionadas con la comunicación visual. En esta medida, se hace uso de la metodología del grupo focal, donde se reúne a cinco profesionales de la provincia, destacados en el área, quienes disertan sobre temas relacionados al arte, fotografía, publicidad, arquitectura y diseño. Asimismo, se apoya en el análisis de contenido y la revisión bibliográfica y documental de las memorias registradas del evento. Como resultado se ofrece una aproximación al imaginario colectivo que existe en Machala, cuyas bases se cimentan bajo premisas de consumismo, adoctrinamiento de culturas ajenas y desplazamiento del valor estético local.

Palabras clave: cultura visual, identidad, Machala, comunicación visual.

\section{ABSTRACT}

This research paper presents an approach to the state of Visual Culture in Machala, province of El Oro, through an analytical study with contextual bases. Its objective is to explore the contemporary vision of the canton from different angles of reflection related to visual communication. To this extent, the methodology of the focal group is used, where five professionals from the province, who are prominent in the area, met to discuss topics related to art, photography, advertising, architecture and design. Likewise, it is supported by the content analysis and the bibliographic and documentary review of the recorded memories of the event. As a result, we offer an approach to the collective imaginary that exists in Machala, whose foundations are based on premises of consumerism, indoctrination of other cultures and displacement of the local aesthetic value. This proposal was born in the career of Social Communication of the Technical University of Machala in response to the demand of readers of more agile, astute and coherent signs.

Keywords: Visual Culture, identity, Machala, visual communication.

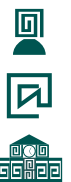

Cristhian Eduardo Rivera Orbe

ceriverao_est@utmachala.edu.ec

Universidad Técnica de Machala

\section{Paula Belén Moreno Sánchez}

pmoreno_est@utmachala.edu.ec

Universidad Técnica de Machala

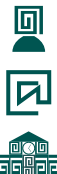

Gabriel Antonio Íñiguez Parra

giniguez@utmachala.edu.ec

Universidad Técnica de Machala

Laddy Lisseth Quezada Tello

lquezada@utmachala.edu.ec

Universidad Técnica de Machala 


\section{INTRODUCCIÓN}

Gran parte del contexto en el que la sociedad se desarrolla está plagado de imágenes, ilustraciones y contenido visual en general. El cine, el arte, la pintura, la escultura son algunas de las manifestaciones de un tipo de lenguaje que está instituido, fundamentalmente, de signos. A toda esa agrupación de imágenes que las personas procesan día tras días (muchas veces sin ser conscientes de ello) se la conoce como Cultura Visual. Su enfoque multidisciplinario aborda un amplio espectro de imágenes manipuladas por el hombre. De acuerdo al criterio de Costa, "un mensaje gráfico, como el plano de la ciudad, un cartel o un libro de cocina, está ahí fundamentalmente para transmitir informaciones. Y esta función comunicativa deviene precisamente de su naturaleza visual" (2014:93). En ese sentido, la importancia de procesar estos signos se desploma sobre la forma de acción que tiene en los seres humanos, pues estos permiten crear interacción con el mundo, ofreciendo diferentes formas de entenderlos desde la propia construcción de la razón, en respuesta a los estímulos visuales que se consumen.

El consumidor, por su parte, busca una sola cosa: satisfacer el hambre de conocer. Busca información constantemente y en su búsqueda en muchas ocasiones no opera bajo criterios analíticos, sino únicamente a un modelo de respuesta adoctrinado inconscientemente. En este mismo marco, la percepción del ser humano habita en un gigantesco mar de signos cuya decodificación crea la estructura de la conciencia.

A través de este universo de signos, construimos una representación de la realidad, que tiene el sello de las circunstancias espaciotemporales y los códigos culturales compartidos. Entonces, existe un código y una realidad percibida a través de ese código, una realidad filtrada por medio de ese simbolismo, que nos permite ver esa realidad, aunque sea parcialmente, pero es lo único que tenemos (Fernández 2011:50).
Partiendo de todo lo expuesto, el coloquio de Cultura Visual explora diferentes áreas enmarcadas a los leguajes visuales como la fotografía, el diseño gráfico, la publicidad, las artes y, en general, los procesos inmiscuidos en la narrativa visual. La realización de este evento en la ciudad de Machala, capital de la provincia de El Oro, busca, a través de una perspectiva semiótica, ampliar la visión que la gente tiene sobre el contenido visual que rodea su entorno. Flechsig y Schiefelbein sentencian, que, respecto a la realización de un coloquio, este se trata de un "aprendizaje recíproco, (donde) cada participante aporta y, también, recibe experiencias, aunque los aportes sean cuantitativa y cualitativamente diferentes" (2003:31).

De esta manera, el evento permite la reflexión acerca de temas propios de la cultura visual, además de promover la sensibilización en las personas sobre las influencias que los contenidos visuales, inmersos en la iconósfera, tienen sobre su propia conducta. A groso modo, el primer coloquio de Cultura Visual busca capacitar a los asistentes a ser mejores lectores de imágenes, críticos y constructores de conocimiento a través de la socialización de experiencias $\mathrm{y}$, más puntualmente, del contenido recogido durante el evento. Es preciso aclarar que el desarrollo de eventos que permitan a los actores principales de un área temática, interactuar y acercar con la ciudadanía y la academia, son de gran importancia para la toma de conciencia de las posibilidades que existen al trabajar de manera interdisciplinaria en la gestión de la cultura visual.

\section{METODOLOGÍA}

La investigación realizada es de orden cualitativo y está basada en un enfoque dialéctico, por tanto, se encarga de reflexionar 
y discutir sobre los resultados recogidos tras la ejecución del primer coloquio de Cultura Visual realizado en la ciudad de Machala, provincia de El Oro, donde se aplica la observación directa y la revisión bibliográfica de las memorias del coloquio registradas por el moderador. Este escenario propició un ambiente de intercambio de ideas, saberes y experiencias de cada uno de los involucrados, lo que permitió la interpretación, análisis y síntesis de los criterios de expertos abordados durante la participación de cinco exponentes en materia de comunicación visual, desde los campos de la fotografía, el diseño y el arte, a fin de promover una reflexión sobre las prácticas de procesos de decodificación visual y su impacto en la conducta humana. El coloquio, se centró en la socialización de nuevos conocimientos y experiencias (Flechsig y Schiefelbein 2003), por tanto, se promueve un aprendizaje a través de conversaciones estructuradas, que se llevan a cabo según reglas acordadas.

Para el desarrollo del evento, existió un moderador -autor principal de este artículo-, quien se encargó de puntualizar y registrar las intervenciones de cada expositor y referir las reflexiones más trascendentes a los asistentes. Esta investigación se estructuró en dos fases:

\section{PRIMERA FASE}

- Acopio de información de los perfiles de posibles ponentes para el coloquio.

- Entrevistas no estructuradas con personajes de la comunicación social y visual referentes al tema en cuestión.

\section{EXPOSITORES}

La consideración de los perfiles profesionales se basó en la identificación de la tra-

Tabla 1.- Expositores y temas del Primer Coloquio de Cultura Visual

\begin{tabular}{|c|c|c|}
\hline Exponente & Profesión / actividad & Tema \\
\hline Miguel Zhunio & Arquitecto & Cultura visual en el diseño y la rotulación. \\
\hline Mathew Avecillas & Fotógrafo & $\begin{array}{l}\text { La fotografía de modas como sistema de } \\
\text { cultura visual. }\end{array}$ \\
\hline Jorge Manríquez & $\begin{array}{l}\text { Promotor y gestor } \\
\text { cultural orense }\end{array}$ & $\begin{array}{l}\text { La cultura visual como expresión estético- } \\
\text { comunicativa en la sociedad. }\end{array}$ \\
\hline Iván Cruz & Arquitecto y escultor & La estética de la escultura en la cultura visual. \\
\hline Andrés Bastidas & Diseñador gráfico & $\begin{array}{l}\text { La cultura visual desde la expresión del } \\
\text { tatuaje. }\end{array}$ \\
\hline
\end{tabular}

Fuente: elaboración propia, recogida a partir de las ponencias y temáticas del primer coloquio de cultura visual. 
yectoria y contribución al mundo visual de cada uno de los ponentes. Se consideró una lista extensa de candidatos, de los cuales se fueron filtrando los seleccionados. A continuación, se describe la tabla de expositores y temáticas.

\section{SEGUNDA FASE}

- Exposiciones en diálogo directo con los asistentes, a través de la puesta en escena del coloquio.

- Debate final analítico respondiendo a inquietudes presentadas durante las intervenciones de los ponentes por parte de los asistentes.

- Registro de las memorias del evento por parte del moderador para posterior difusión.

\section{PÚBLICO}

Los asistentes que formaron parte de este primer evento estuvieron conformados por estudiantes y docentes de la Unidad Académica de Sociales de la Universidad Técnica de Machala, en especial de las carreras de Comunicación Social y Artes Plásticas; así mismo, se hizo visible la presencia de varios profesionales del área de Diseño Gráfico y Comunicación Visual que ejercen dentro de la provincia de El Oro. Un aproximado de 220 personas participó directamente en las instalaciones del ECU 911, Machala.

\section{RESULTADOS Y DISCUSIÓN}

Al hablar de temas relacionados al campo visual, se debe considerar que es un área, en estado de cambio y transformación. Este proceso es evolutivo y sus bifurcaciones están sometidas a resignificación constante.

A continuación, se plantean modelos de reflexión sintetizados en 4 ejes sobre los que estribó el primero coloquio de Cultura Visual. Estas consideraciones se argumentan sobre las bases de los expositores y una revisión del estado del arte afín.

\section{Sobre diseño y publicidad}

El mundo contemporáneo está marcado por la hipervisualidad. Este concepto describe una realidad plagada de imágenes que, dondequiera que se mire, se multiplican minuto a minuto abarcando cada vez más espacio. En la sociedad del consumo actual, se está expuesto a la cultura visual voluntaria o involuntariamente; de la misma forma, siento parte de este entorno, se aprendió a conocer el significado de las imágenes dentro del contexto, que procede de nuestras propias construcciones, en el que los individuos interactúan en su diario convivir, permitiendo decodificar y se descifra el medio.

No en vano uno de los consejos que sugiere Costa para un correcto diseño de comunicación visual es "adaptar la estrategia comunicacional y el lenguaje visual a la cultura media del grupo destinatario, a sus códigos generacionales o profesionales y a sus expectativas" (2014:106). Este criterio refleja la idea, de forma más clara, de cuán importante es tener en cuenta el carácter voluble de los signos, pues en materia social, los estudios son pertinentes realizarlos con mucha regularidad.

Ahora bien, dentro de todo este proceso de decodificación -que dependerá del bagaje cultural de quien observe-, hay que tener en cuenta que esas interpretaciones se desarrollarán en función del imaginario colectivo, sea focalizado o generalizado ante un concepto muy amplio. Desde esta perspectiva, es importante señalar que mucho de este contenido fue creado por la mano del hombre, a través de un procedimiento de rigurosa minuciosidad, de manera que pasó por una fase de manipulación previa que le dotó de un significado intencional desde su identidad; de esta característica 
se han valido creaciones visuales en áreas como la publicidad y el diseño, en los temas relacionados con la fotografía, sea de moda o artística, e incluso ante la rotulación de emblemáticas marcas.

Al considerar la postura teórica de Galán y Ramírez respecto al tema, es posible observar cómo en la actualidad, la lectura de imágenes se posiciona "en la discusión teórica de las ciencias del lenguaje que se enfrenta a nuevas formas de comunicación donde el arte y la tecnología transforman la experiencia humana hacia paisajes que apenas se vislumbran". (2013:53)

\section{Sobre la fotografía, la moda y los este- reotipos}

Cuando se aborda el avance en el tiempo, no se puede dejar de lado el progreso tecnológico que rodea todo el mundo visual. En términos generales, el mundo digital llegó a potenciar infinitamente las posibilidades existentes para un comunicador visual del pasado.

La digitalización no se limita a ejercer su influencia sobre las industrias culturales tradicionales heredadas de la sociedad industrial (libro, música, cine) y los medios de comunicación (prensa, radio, televisión), sino que también produce nuevas lógicas y cambios en el paradigma de la comunicación (Duran 2017:15).

Lo que se percibe a través de las imágenes que un colectivo acepta como referente puede llegar a configurar la mente humana, haciendo fácil su réplica. Estas repeticiones comienzan a escabullirse hasta puntos recónditos, llegando a todos lados e instaurándose en la conciencia humana, de tal manera que es así como se comienzan a formar los estereotipos. Es importante prever el alcance y el impacto que estos paradigmas tendrán en el espectador, pues la creación de estereotipos es también otra de las problemáticas ampliamente aceptadas (y criticadas) por el mundo.

La edición digital hoy en día es muy empleada y muchas veces necesaria para poder llegar a transmitir un mensaje de forma adecuada. Es pertinente que el profesional en fotografía y diseño esté al tanto del proceso digital que consiste en el retoque. Sin embargo, la utilización excesiva de estas técnicas ha influido en forma negativa a establecer los estereotipos en las sociedades. Avecillas, fotógrafo ponente del coloquio, afirma que el establecimiento de estos estereotipos en la sociedad comienza con los niños, que se alimentan de lo que ven todos los días en la televisión, para lo cual los padres cumplen un papel fundamental en este ámbito, supervisando lo que sus hijos consumen como espectadores.

A estas mismas razones, el abuso del Photoshop ha sido uno de los factores para que este estereotipo de "mujer perfecta" se haya plasmado. Un estereotipo común en la sociedad es el de la mujer, la cual debe cumplir con varias características estándares de belleza, ignorando en totalidad la subjetividad propia de la visión humana. Las mujeres al sentir que no cumplen con el estereotipo de las revistas de moda, televisión, etc.; llegan a frustrar su pensamiento, trayendo como consecuencia varios trastornos como la anorexia, bulimia, entre otros.

A este análisis, se suma el criterio de González, quien asegura que "se muestra a las mujeres únicamente como musas, utilizando su imagen de inspiración divina y artística" (2016:3), lo que claramente trasciende en una mirada poco profunda y orientada a la cosificación en términos de humanidad.

La representación del género femenino ha estado tradicionalmente en manos de los hombres, lo que ha convertido a la figura 
femenina en la protagonista pasiva de la historia del arte. (...) El papel de la mujer en la fotografía fue por ello reducido durante mucho tiempo a modelo situado ante la cámara, objeto que fotografiar (González 2016:10).

\section{Sobre la tecnología en la propagación de contenido visual}

En esa misma línea Madrigal Romero, considera que, a causa del creciente modo de evolución de la tecnología, se "ha generado cambios profundos que afectan al ámbito de la comunicación y la publicidad" (2015:7). Para lo cual sentencia a las redes sociales, argumentado que su uso es cada vez más amplio, tanto así que se llegaron a obligar a las marcas a participar activamente para interactuar con su público objetivo. Ante ello, Solís considera que el contenido visual debe ser entendido como un "elemento retórico", cuyo contenido permite transmitir contenidos "utilizando elementos visuales distintos al producto o servicio anunciando, lo que ofrece grandes posibilidades creativas para trasmitir con una sola imagen un amplio contenido". (2017:117)

La metáfora permite establecer una complicidad con el receptor de la comunicación, que toma una postura activa en el proceso comunicacional gracias a que éste requiere su participación para que dé una interpretación a la figura retórica propuesta en el anuncio. En esta nueva comunicación la metáfora visual ofrece al consumidor un mensaje abierto y es necesaria su intervención para descifrar qué le quieren transmitir a través de la imagen metafórica (Solís 2017:118).

Al partir de esta postura, se infiere que la cultura visual permite establecer una relación de entendimiento con el entorno, de manera que influye a la hora de entender el mundo. El contenido visual que hayamos incorporado, crea una serie de referentes de cualquier elemento en contexto, marcando el paso a la interacción con el ambiente en que se esté y condicionando nuestras acciones dependiendo del estímulo. Por ejemplo, si una niña crece en una casa donde pintarse los labios es algo común, puesto que la mamá, las tías y las hermanas lo hacen continuamente, y ven tutoriales de maquillaje, revisan revistas de moda, miran a famosas en redes sociales hacerlo, no será tan difícil imaginar que esta niña también lo haga. En este caso, la cultura visual a la que está expuesta la niña es una y sus acciones, a veces sin la menor reflexión, la orientan al mismo propósito.

Estas consideraciones también se extienden al campo audiovisual, donde la conformación de cápsulas de video adoctrina millones de nuevos fanáticos al día. En este sentido, se debe analizar el objetivo de los mensajes, pues como se mencionó anteriormente, la construcción del mismo obedece a una intención. Sus formas de construcción se gestan no solo desde perspectivas individuales que revelan la intencionalidad de todo este proceso, sino que también se enganchan al punto de viste al que dirigen su "engranaje de transmisión" (Grau 2010:7). De acuerdo a Durán; “con la digitalización se inicia un proceso de mayores sinergias entre la comunicación y la cultura", cuyo resultado podría derivar en una "nueva convergencia entre las políticas de comunicación y las políticas culturales" (2017:14). Esto en consecuencia contribuye a la creación de patrones de conducta ajenos al propio, y al adoctrinamiento de ideologías externas.

Este tema es materia de debate desde años atrás, al respecto Galán y Ramírez aseguran que, debido al crecimiento de los discursos en el mundo visual en la era contemporánea, "recientemente se han incorporado a la discusión la semiótica y la hermenéutica, junto 
con las psicologías de la imagen y otras teorías de la comunicación" (2013:48). En un primer análisis parecía un tema sujeto a carreras de comunicación y artes únicamente, no obstante, su resultado se abre paso por más áreas relativas a la sociología puesto que el fenómeno que se genera en la sociedad es gigantesco y, a día de hoy, no tiene rasgos de detenerse.

\section{Sobre el tatuaje como simbolismo}

Por otro lado, en lo relativo a la narrativa visual del tatuaje, la historia del mismo se remonta siglos atrás, cuando los tatuajes de aquella época gozaban de suma importancia. Su uso obedecía a un orden jerárquico, y muchas veces se empleaban para impresionar a los enemigos en el campo de batalla. Se cree que los que poseían tatuajes antiguamente eran los más cotizados, pues además de ofrecer un rasgo distintivo, algunas veces se ofrecieron dar armas a cambio de las cabezas de los tatuados, así el cortar la cabeza del enemigo dejo de ser un honor y se convirtió en comercio (Sierra 2009:314).

Algunos cientos de años después, el poseer un tatuaje revelaba que pertenecías a cierto grupo social, bien sea un presidiario, o relacionado a la prostitución, marinos o guerrilleros. Incluso en los 70 esta creencia se volcó sobre la gente que era expendedora y consumidora de drogas. Pero como ya se ha abordado, este proceso visual no está exento de mutar en el tiempo. Y eventualmente su significación comenzó a cambiar también, llegando a considerarse desde otras aristas de la investigación y análisis, tomando como valor agregado la significación personal, rasgo inherente de la cultura, que esta posee.

La práctica del tatuaje, como expresión cultural, constituye un espacio donde confluyen dos tipos de memoria, una común que se desarrolla como contexto de las condiciones de producción y una individual, un espacio de la intimidad y otro donde el texto responde a necesidades particulares y específicas (Álvarez 2002:2).

Desde esta postura, el tatuaje experimentó un considerable incremento en la época contemporánea, pasando de ser un castigo y relacionarse a simbolismos de anarquía y represión, a ser una tendencia de modas. (Álvarez 2002:3) estima que entre un 3 y un $8 \%$ de la población general tiene tatuajes. Para este siglo, la expresión de tatuarse se configura como una práctica humana de tintes culturales. Walzer asegura que "entre los siglos XIX y XX comienza de forma progresiva su expansión en los países occidentales inicialmente asociado a grupos específicos y constituyendo, en ocasiones, una seña de marginalidad o diferenciación" (2015:195), sin embargo este cambio se extiende y es objeto de innumerables apuntes pues su propia forma de expresión refleja una significación que ningún otro tipo de expresiones posee.

A día de hoy, tener un tatuaje ya no representa ningún tipo de digresión a la honra o "encaje" en determinado grupo social, sino más una expresión propia de la humanidad de uno mismo. Para el sentido de este coloquio, se detalló que el tatuaje constituye un reflejo de la identidad, un signo de identificación, propio e invariable, que se tendrá de por vida. 


\section{CONCLUSIONES}

- Durante muchos años en Machala se tuvo la idea de que dentro de este territorio no existía ningún tipo de impulso en el área visual, siendo este un criterio impreciso, pues Machala tuvo actores visuales desde siempre.

- El machaleño cambió, creció, la perspectiva del diseñador o creador visual maduró y pasó de una postura infravalorada, a convertirse en la actualidad en un actor importante en la construcción de identidades.

- Al abordar el consumo en la capital orense, los medios masivos favorecen a la creación de estereotipos, donde los portavoces se encargan muchas veces, de distribuir una realidad ficticia, inventada, ajustada a estándares de estética rígidos y poco comunes en la mayoría de las personas. Su cadena de signos orienta la visión machaleña a la creación de tendencias ajenas, que dejan de lado el carácter propio de su gente.

- El tatuaje, como manifiesto visual, sirve como distintivo propio de una identidad, pues en este marco la cultura visual no es un fenómeno moderno, sino cultural. Desde hace siglos que muestra la historia, trascendencia, valentía, miedos, salud o la simple vanidad de las naciones.

- En la comunicación visual, tanto los artistas como los diseñadores constituyen elementos claves para la creación de identificadoras visuales. Su trabajo se encarga de mostrar la comunicación desde una perspectiva diferente; en el primer coloquio se confirmó que, bien sea arte o publicidad, se comunica bajo una perspectiva de sensibilidad y humanismo que pretende apelar el lado emocional del ser humano.

- En el mundo visual, la imagen, las formas y demás elementos plantean la necesidad de implantar un nuevo sistema de comunicación, regidos bajo unas condiciones de esté- tica (belleza), estabilidad (seguridad, coherencia) y de funcionalidad (uso) que muchas veces no consideran el contexto, ofreciendo generalidades poco acertadas.

- La visión del machaleño sobre su propia cultura es aún incipiente y se encuentra en crecimiento, a la par que las personas dedicadas a la comunicación visual comienzan a tomar cada vez más fuerza.

- La realización del coloquio de Cultura Visual es de gran impacto en la comunidad orense relacionada con el tema de la comunicación visual, pues ofrece una ampliación al mundo de las artes, el diseño y la fotografía, cuyo resultado se traduce en: si se es productor de contenido, ofrecer mejor calidad; y si se es consumidor, ser más selecto a la hora de elegir qué consumir. De manera extensa, el coloquio también abre debate en términos de razonamiento y consideración del infinito mar de signos que rodea una sociedad. 


\section{REFERENCIAS BIBLIOGRÁFICAS}

Álvarez Licona, N. E. \& Sevilla González, M. D. L. L. (2002). Semiótica de una práctica cultural: el tatuaje. Cuicuilco, 9(25).

Costa, J. (2014). Diseño de Comunicación Visual: el nuevo paradigma. Gráfica, 2, 89 - 107.

Durán, J. B. (2017). Los nuevos escenarios de la cultura de la era digital. España: UOC.

Fernández, S. R. (2011). La interminable resignación del suceso artístico. Educación, Arte y Signo. Actas de las Segundas Jornadas Internacionales Peirceanas, $50-59$.

Flechsig, K.-H. \& Schiefelbein, E. (2003). Veinte Modelos Didácticos para América Latina. interamer digital 72, 31 - 34 .

Galán, C. F. \& Ramirez, J. G. (2013). La lectura de la imagen ¿Semiótica o hermenéutica? Imaginario Visual 4, 49 - 53.

González-Moreno, M. B. (2016). Fotografía, mujer e identidad: Imágenes femeninas en la fotografía desde finales de los 60 (Tesis Doctoral, Universidad de Granada, Granada, España). Recuperado de: https://hera.ugr.es/tesisugr/26400030.pdf

Grau, J. (2010). El audiovisual como refracción cultural. Nuevas tendencias en Antropología.

1, 1-20. Recuperado de: http://www.revistadeantropologia.es/Textos/E1\%20audiovisual $\% 20$ como $\% 20$ refraccion $\% 20$ cultural.pdf

Madrigal Romero, C. (2015). Instagram como herramienta de comunicación publicitaria: el

caso de Made With Lof. (Trabajo fin de grado inédito, Universidad de Sevilla, Sevilla, España). Recuperado de: https://docplayer. es/24477646-Instagram-como-herramienta-de-comunicacion-publicitaria-el-caso-de-made-with-lof.html

Sierra, X. (2009). Tatuajes. Un estudio antropológico y social. Piel, 24(6), 314-324. Recuperado de: http://escuelasuperior.com.ar/instituto/ wp-content/uploads/2015/10/tatuajes.pdf

Solís, F. M. (2017). Metáfora Visual, elemento comunicador de las marcas en la publicidad exterior. Prisma Social, 117 -137.

Walzer, A. (2015). Tatuaje y significado: en torno al tatuaje contemporáneo. Revista de Humanidades, 24 193-216.
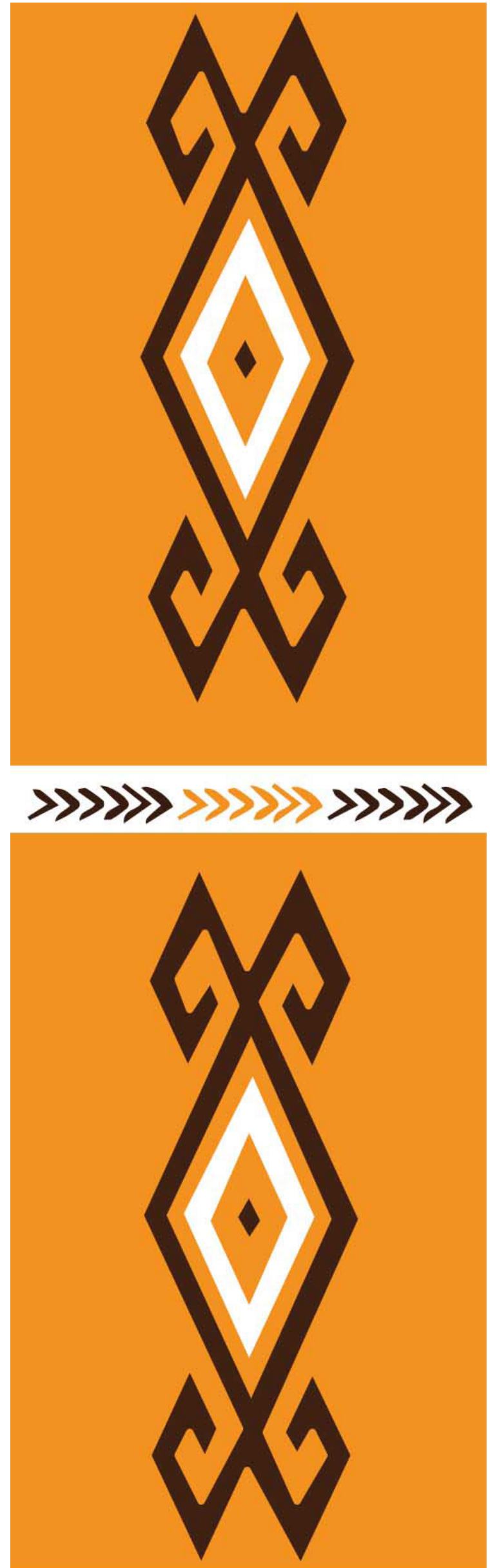